University of Wollongong

Research Online

Faculty of Engineering - Papers (Archive)

Faculty of Engineering and Information

Sciences

October 2005

\title{
Modelling blast loads on buildings in complex city geometries
}

Alexander Remennikov

University of Wollongong, alexrem@uow.edu.au

T. A. Rose

Cranfield University, UK

Follow this and additional works at: https://ro.uow.edu.au/engpapers

Part of the Engineering Commons

https://ro.uow.edu.au/engpapers/353

\section{Recommended Citation}

Remennikov, Alexander and Rose, T. A.: Modelling blast loads on buildings in complex city geometries 2005.

https://ro.uow.edu.au/engpapers/353

Research Online is the open access institutional repository for the University of Wollongong. For further information contact the UOW Library: research-pubs@uow.edu.au 


\title{
Modelling blast loads on buildings in complex city geometries
}

\author{
$\underline{\text { Alex M. Remennikov }}^{1}$ and Timothy A. Rose $^{2}$ \\ ${ }^{1}$ School of Civil, Mining and Environmental Engineering, Faculty of Engineering, \\ University of Wollongong, Wollongong NSW 2522, Australia \\ Phone: (61-2) 4221-5574, fax: (61-2) 4221-3238, email: alexrem@uow.edu.au \\ ${ }^{2}$ Engineering Systems Department, Cranfield University, Royal Military College of \\ Science, Shrivenham, Swindon, SN6 8LA, UK
}

\begin{abstract}
This paper is concerned with an accurate prediction of the effects of adjacent structures on the blast loads on a building in urban terrain. Blast loadings on structures have typically been evaluated using empirical relationships. These relationships assume that there are no obstacles between the charge and the target. In real situations, the actual blast loads can either be reduced due to shadowing by other buildings or can be enhanced due to the presence of other buildings in the vicinity. Results of the numerical simulations presented in this study for multiple buildings in an urban environment have demonstrated the importance of accounting for adjacent structures when determining the blast loads on buildings. An approach to determining the enhancement factors is described.
\end{abstract}

Keywords: blast loads, urban environment, explosion, numerical simulation

\section{Introduction}

Protecting civilian buildings from the threat of terrorist activities is one of the most critical challenges for structural engineers today. Events of the past few years have greatly heightened the awareness of structural designers of the threat of terrorist attacks using explosive devices. Extensive research into blast effects analysis and techniques to protect buildings has been initiated in many countries to develop methods of protecting critical infrastructure and the built environment. The private sector is also increasingly 
considering measures to protect so-called "icon buildings" against the threat of external terrorist bomb attacks.

There are a number of means available to help prevent a successful terrorist attack on a building. One of the most effective measures consists of gathering intelligence that can be used to stop an attack before it takes place. Another measure that can be used to protect many new and existing buildings is the design and retrofit of structures, which can resist blast loadings and protect occupants. This area of research is currently receiving a great deal of attention by the engineering community.

Although it is recognised that no civilian buildings can be designed to withstand any conceivable terrorist threat, it is possible to improve the performance of structural systems by better understanding the factors that contribute to a structure's blast resistance. One such factor is the ability of the structural designer to accurately predict the blast loadings on structural components using analytical or numerical tools that take into account the complexity of the building, the presence of nearby structures and the surrounding environment.

Historical records indicate that the majority of terrorist incidents have occurred in an urban environment in the presence of nearby buildings forming the street geometries. Intuition suggests that the peak pressure and impulse associated with the blast wave should be higher in narrow streets, compared to wider ones. In fact, it has been observed that the confinement provided by tall buildings could drastically increase the blast loads by an order of magnitude or more above that produced in the free field by the same explosion source. However, systematic quantification of these effects has only recently been addressed by a few researchers [1-3], and they are still not described satisfactorily over a wide range of possible distances and street configurations. 
The aim of this paper is to demonstrate the importance of considering the effects of congestion between buildings on blast loading and to present numerical techniques to predict the loads on buildings in an urban environment.

\section{Existing experimental and numerical results}

\subsection{Experimental evidence of the effect of street confinement}

Smith, et al. [4] have presented the results of a small-scale experimental investigation of a number of generic street configurations. One of the experiments involved construction of a straight street model from reinforced concrete blocks, terminated by a simple T-junction formed from a cubic building made of steel. The test set-up also included charges of about $7 \mathrm{~g}$ of plastic explosive, which were placed in the middle of the street. The charges were placed at different scaled distances $Z\left(=R / W^{l / 3}\right.$, where $R$ is the range from the charge, and $W$ is the equivalent charge mass of TNT) from the building at the end of the street. The measured peak reflected overpressure values for two configurations, where the street buildings were first present and then removed. Figure 1 clearly demonstrates the considerable pressure enhancement by a factor up to four as a result of confinement provided by buildings along the street.

The effect of confinement on the positive and negative phase blast wave impulses was studied experimentally and numerically by Rose and Smith [2]. Straight street configurations with different widths and different heights have been investigated experimentally to validate findings of the numerical studies. The selected configurations were representative of relatively small and large street width, together with relatively low to very high building heights. The layouts of the experiments were chosen to represent a scaled version of a realistic threat where a $1000 \mathrm{~kg}$ TNT charge is detonated in the middle of the street. The experiments were performed at a one-fortieth 
scale. The explosive charge was $15.6 \mathrm{~g}$ of TNT equivalent. The models were constructed from reinforced concrete beams, some of which had pressure transducer mounts cast into one face. The outcome of these studies confirmed that the positive phase impulse is enhanced significantly above the equivalent reflected impulses calculable from scaled blast parameters such as those contained in design manuals $[5,6]$, and the enhancement is dependent on the street width and the building height. These studies also established that the negative phase impulse is affected by the confinement effect but in a less straightforward way than the positive phase impulse.

\subsection{Computer code validation for blasts in urban terrains}

Blast loads in simple geometries can be predicted using empirical or semi-empirical methods, such as those presented in the design manuals $[5,6]$. For a review of methods for predicting the blast effects on a building in a simple geometry see [7]. These can be employed when blast load prediction on an isolated structure is required. In more complex geometries typical of modern city central business districts (CBDs), one approach is to use three-dimensional hydrocode or Computational Fluid Dynamics (CFD) calculations using numerical tools such as AUTODYN [8], CTH [9], SHAMRC [10], or Air3D [11] to provide reliable estimates of the effects of adjacent structures on the blast loads on buildings in CBDs.

Experiments have been conducted to validate the numerical simulation techniques against blast load experimental results. Fairlie [12] has experimentally evaluated the channelling of a blast wave in a crossroads type geometry and compared the experimental and numerical peak pressures and impulses against the results predicted by AUTODYN. It was demonstrated that numerical results for the crossroads configuration agreed to within 15 per cent for peak pressures and positive phase impulses. Computer codes Air3D and SHAMRC have also been validated for 
predicting free-field airblast pressure histories as well as blast loads in more complex street geometries $[2,10]$.

The disadvantage of using numerical modelling to predict blast loads on buildings is the computer resources that are required for precise and reliable simulations. To resolve accurately the peak pressures and impulses, three-dimensional simulations ideally use a computational domain on the order of $10^{6}-10^{7}$ cells or more. For example, the multiple building blast simulation described by Bevins [13] used the model with 38 million cells. The 25 msec simulation required 160 hours on 23 processors of the Compaq SC45 supercomputer. For those without access to a supercomputer, it would be more practical to break up a larger problem into smaller detailed analyses that cover different scaled ranges.

\section{Multiple Building Numerical Simulation}

Several experimental and numerical studies [2-4] have demonstrated that the blast loads on a building are affected by the presence of adjacent structures. Whether the blast loads are reduced due to shadowing by other buildings or augmented due to reflection and channelling of the airblast pressure is generally determined by the design of the buildings, the layout of nearby streets, and the location and size of the explosive device.

A limited number of experiments involving small-scale models have been conducted to validate numerical simulations of blast wave - multiple structures interaction $[4,14]$. A combined experimental-analytical approach has proven to be the most economical way to investigate the phenomenology of blast wave propagation in complex city terrains. Numerical simulations can be used to extend the database of blast effects in urban terrains by varying the parameters in numerical models. Moreover, analyses can be performed for cases where experiments cannot be performed or where the required design information cannot be extracted from experimental results. Based on the results 
of the simulations, validated and improved methods can be developed for predicting blast loads on buildings in congested city environments.

Better to understand the phenomenology that affects the blast loads on a structure, numerical simulations were performed using the Australian Partnership for Advanced Computing (APAC) High Performance Computing (HPC) facilities. The computer code Air3D [11], compiled to run on the Compaq AlphaServer SC45 system, was used to perform a series of airblast calculations in this paper. Air3D uses an explicit, finite volume formulation to solve one-, two- and three-dimensional forms of the Euler equations. The computational grid uses cubic cells in a regular Cartesian mesh.

\subsection{Two-building simulation}

Shielding effects and reflection of pressure off the adjacent structures were studied in the two-building simulation. Two target buildings and the geometric parameters of the model are shown in Figure 2. The two-building model represents a scenario where the explosive charge of $W \mathrm{~kg}$ of TNT equivalent is detonated at close range from a smaller building (Building 1) that provides partial shielding to an adjacent larger building

(Building 2). The scaled standoff distance to Building 1 is $Z_{1}=R_{1} / W^{1 / 3}=0.5 \mathrm{~m} / \mathrm{kg}^{1 / 3}$, and the standoff distance to Building 2 is $Z_{2}=1.0 \mathrm{~m} / \mathrm{kg}^{1 / 3}$. The height of the buildings was also scaled by the cubic root of the explosive weight, $W$, in order to be used as the design parameter. In the model, the centre of the explosive charge was in line with the centres of the target buildings.

The buildings were modelled as rigid reflective surfaces. Typical simulation of blast wave - rigid building interaction with Air3D includes three stages with automatic remapping between each stage: (1) one-dimensional analysis for the spherically symmetrical region between the centre of the explosive charge and the ground, if the high explosive (HE) source is detonated above the ground level; (2) two-dimensional 
blast wave propagation for the radially symmetrical region from the time when the blast wave reaches the ground level to when it reaches the nearest surface of the target building; and (3) three-dimensional analysis to capture such effects as multiple reflection, diffraction, blast focusing and shielding.

The two-building model comprised about 5,000,000 $\times 10 \mathrm{~mm}$ cubic cells. The threedimensional model was extended in each direction so that the presence of boundaries did not affect the results of analyses. The target points, where blast pressure and impulses were measured, were distributed over the front and rear walls of the buildings. The 10 msec simulation required 15 hours on the Compaq AlphaServer SC. The results of the two-building simulation were compared against a baseline model, in which only the second building was present to accentuate the effects of blast wave interaction with a group of buildings. All the simulations took advantage of a symmetry plane through the centre of the two buildings and the hemispherical charge that effectively reduces the model size by a factor of two.

\subsection{Collateral blast effects due to blast focusing}

The street layout adopted for the simulation of collateral blast effects is shown in Figure 3. A hemispherical explosive charge of $W \mathrm{~kg}$ of TNT was placed in the middle of the street at the ground level at a standoff distance of $0.5 \mathrm{~m} / \mathrm{kg}^{1 / 3}$ from the nearest building bordering the street, which is designated as the Primary Target building in Figure 3. A standoff distance to the Secondary Target building at the T-junction was $R$ $\mathrm{m}$. This allowed investigation of the blast wave propagation along the street for the scaled street distances up to $R / W^{1 / 3}=10 \mathrm{~m} / \mathrm{kg}^{1 / 3}$. The scaled height of buildings bordering the street was varied from $h / W^{1 / 3}=1.0 \mathrm{~m} / \mathrm{kg}^{1 / 3}$ to $4.0 \mathrm{~m} / \mathrm{kg}^{1 / 3}$ with a 1.0 $\mathrm{m} / \mathrm{kg}^{1 / 3}$ increment. The height of the secondary target building at the opposite end from 
the explosion was kept constant at $1.5 \mathrm{~m} / \mathrm{kg}^{1 / 3}$, which is indicative of a medium-sized shopping mall building.

The street numerical model consisted of about $18,000,000 \times 0.3 \mathrm{~m}$ cubic cells. The 250 msec simulation required about 35 hours to complete each analysis on the AlphaServer SC45 system. The simulation took advantage of symmetry through the centre of the street. In addition to the street layout simulation, the free-field blast parameters for a surface burst charge were derived analytically for the pressure measuring points along the centre of the street and at the surface of the secondary target building thereby ignoring the presence of the surrounding buildings.

\section{Discussion of results}

\subsection{Two-building simulation}

Visualisation of pressure contours available during the post-processing stage allows a better understanding of the complex process of blast pressure interaction with a group of buildings. Figure 4 shows the blast pressure contours at the ground level $0.792 \mathrm{msec}$ after detonation. By this time, blast pressures have wrapped around the corners of the front wall, moved down the side wall, and wrapped around the rear wall of the first building.

The shocks travel around the opposite sides of Building 1 and meet near the centre before reaching Building 2. By $1.27 \mathrm{msec}$ after detonation, the airblast pressure has reflected off the front wall of the back building as seen in Figure 5. Pressure contour plots on a vertical plane through the centre of the buildings are shown in Figure 6. At $1.93 \mathrm{msec}$ after detonation, the airblast pressure has reflected on the rear wall of the first building as a result of the shock reflecting off the second building and propagating back to the rear wall of the first building. 
The pressure and impulse histories measured at the ground level on the rear wall of the first building are shown in Figure 7. This figure shows that the rear wall experienced the second shock, which is about two and a half times as high as the pressure and impulse that initially loaded the building. These results clearly indicate the importance of considering adjacent structures for numerical simulation of the blast loads on buildings in an urban environment. If the presence of the second building were neglected, this would lead to a significant underestimation of the blast loads on the rear wall of Building 1. The pressure and impulse histories in Figure 7 are normalised by the peak pressure and peak positive impulse, respectively, associated with the first pressure pulse.

The relative values of the positive phase and negative phase impulses are also shown in Figure 7. The comparison of the impulses demonstrates that the negative phase impulse is three times greater than the positive phase impulse delivered by the first shock on the rear of Building 1, and twice as much as the positive phase impulse delivered by the second shock. This observation supports an assumption that the negative phase of the blast pulse may have an important influence on lightweight façade panel behaviour by causing the façade material to fail outward.

Figure 8 shows the pressure and impulse histories at the ground level on the front wall of Building 2. The results at this location for the two-building simulation are compared to the pressure and impulse at the same point for the single building simulation, where the first structure was removed from the model, thus exposing the second building to the direct blast effects from the explosion. Pressures and impulses in Figure 8 are scaled by the peak pressure and peak positive phase impulse, accordingly, associated with the two-building model. Thus, the peak reflected pressure on the front wall of Building 2 would be overestimated by a factor of 3.5 if the building in front of it 
were not present. The same is true for the peak positive phase impulse, which would be over-predicted by a factor of 2.6.

\subsection{Collateral blast effects analysis}

Figure 9 shows the effect of scaled building height $h / W^{1 / 3}$ on positive phase pressure and impulse as a blast wave propagates along the street. The graphs compare the peak values of positive pressure and impulse measured at the centre of the street at the ground level for four scaled building heights with the corresponding values for a freefield surface burst of the same hemispherical charge at the same scaled distance. The computer program ConWep [15] was used to make free-field hemispherical predictions for comparison with the Air3D predictions.

It is seen from Figure 9 that the channelling effect along the street is clearly evidenced by the higher pressures and impulses calculated for a street environment compared with those from a free-field surface burst. Considering Figure 9(a), the peak overpressure is significantly enhanced due to multiple reflections from the nearby buildings. It also shows that the pressure-distance relationships for the selected scaled distances are nearly coincident at scaled distances below $Z=5.0 \mathrm{~m} / \mathrm{kg}^{1 / 3}$. At more extended distances from the source, the line corresponding to the scaled building height of $h / W^{1 / 3}=1.0 \mathrm{~m} / \mathrm{kg}^{1 / 3}$ deviates from the remaining curves. This implies that buildings with the scaled height greater than $h / W^{1 / 3}=1.0 \mathrm{~m} / \mathrm{kg}^{1 / 3}$ provide an equivalent level of confinement with respect to the peak overpressure measured along the street. This fact can be used for practical purposes to develop a single pressure enhancement factorscaled distance relationship to account for an urban environment without considering the height of the surrounding buildings.

The effects of partial confinement of a blast wave in a street on positive phase impulse for the selected scaled building heights are presented in Figure 9(b). The street 
positive phase impulses are appreciably higher than the ones for a surface-burst charge in a free-field environment. The curves on the graph become essentially coincident for the scaled building heights $h / W^{1 / 3} \geq 3.0 \mathrm{~m} / \mathrm{kg}^{1 / 3}$. Therefore, this scaled building height can be considered as a limiting level above which the street positive impulses at ground level do not vary appreciably. This finding accords with Rose and Smith's [2] finding that the scaled building height of $3.2 \mathrm{~m} / \mathrm{kg}^{1 / 3}$ is the effective maximum height considered for practical applications. One can also notice a significant reduction in the positive phase impulse beyond the scaled distance of $Z=8.0 \mathrm{~m} / \mathrm{kg}^{1 / 3}$. The corresponding impulse measuring point was located in the middle of a T-junction where the blast wave originating from the street reduced its strength due to diffraction over the vertical corners of the buildings.

Numerical simulations using the Air3D code were used to derive design factors to account for the influence of an urban environment on the blast wave properties as a function of distance. Based on the results depicted in Figure 9, the ratios of the pressure and impulse can be calculated at each scaled distance. Channelling of the blast is shown to increase peak pressure by about 400 per cent and peak impulse by about 500 per cent at extended distances from the source compared with analytical results for the blast wave expanding hemispherically over a flat surface.

The results of numerical simulations have demonstrated that blast waves reflect off the ground and adjacent structures, reinforcing the intensity of the blast's effects. As the blast wave propagates along the street and is about to reach the target building, the positive phase side-on overpressure and impulse are already enhanced by more than 300 per cent compared with the free-field blast wave parameters.

The reflected overpressure time history at the base of the secondary target building is shown in Figure 10. The free-field reflected overpressures predicted by ConWep [15] 
are also shown in this figure. The free-field curve was developed for a hemispherical surface burst of a W-kg explosive charge at a standoff distance of $100 \mathrm{~m}$ without considering the neighbouring buildings. The channelling effect is shown to enhance peak reflected overpressure by 300 per cent compared with the simplified empirical result.

Peak reflected pressure and impulse enhancement factors for the front wall of the secondary target building are shown in Figure 11. Reflected pressure predictions on the front wall were compared with the reflected pressures as computed by ConWep. The enhancement factors were calculated as ratios of numerical and empirical values of peak reflected pressure and impulse at each target point. The target points were along a vertical line at the centre of the front wall. Figure 11 shows that peak pressures are enhanced by a factor of three and peak impulses by a factor of two. The enhancement factor has relatively uniform distribution along the height of the target building. Near the top of the building, the strength of the blast wave is reduced due to diffraction over the roof (usually referred to as clearing), and the enhancement factor is reduced for both pressure and impulse.

It should be noted that values of pressure and impulse enhancement factors which were evaluated from this numerical simulation would be affected by the scaled street width. The numerical experiments [2] have demonstrated that the enhancement is affected significantly by the street width if the scaled street widths $w / W^{1 / 3}<4.8 \mathrm{~m} / \mathrm{kg}^{1 / 3}$.

\section{Conclusions}

The existing engineering-level techniques for calculating the blast effects on buildings are based on the assumption that the building experiences a load estimated assuming that it is isolated in an open space. Historical evidences suggest that the actual blast 
loads can either be reduced due to shadowing by intervening buildings or can be enhanced due to the presence of other buildings in the vicinity.

The presented results for the two-building simulation and their comparison to the simplified methods of evaluating loads on buildings have demonstrated the importance of accounting for adjacent structures when determining the blast loads on buildings in an urban layout.

In this paper, a tentative attempt has been made to characterise the blast environment by considering a simple urban configuration with a relatively long, straight street segment and a T-junction at the far end. Numerical simulations using a computational fluid dynamics (CFD) code Air3D have been used to determine the blast effects on a building in a typical urban terrain. Each simulation provided the variation with distance of peak overpressure and impulse. When compared with the corresponding variations for a surface burst of a hemispherical charge in a free-field environment, these variations allow calculation of the pressure and impulse enhancement factors at each scaled distance from the charge. The resulting enhancement factors can be used effectively to modify the blast parameters obtained from simplified analytical techniques.

The use of both analytical techniques and sophisticated CFD numerical simulations can provide an effective approach to determining blast loads in an urban environment. Further efforts are needed to perform quantitative analysis of the phenomena of blast wave interaction with groups of structures using high performance computing facilities and massively parallel processors. This will lead to improved models for predicting blast effects as well as direct and collateral damage when a structure is subjected to a bomb attack in city centres. 


\section{Acknowledgements}

This work was undertaken as part of a project funded by the University of Wollongong

research grants scheme. The research was conducted using the resources of the

Australian Partnership for Advanced Computing (APAC) National Facility.

\section{References}

1. Rose TA, Smith PD. The influence of street junctions on blast wave impulses produced by vehicle bombs. In: The 11th International Symposium on Interaction of the Effects of Munitions with Structures. 2003.

2. Rose TA, Smith PD. Influence of the principal geometrical parameters of straight city streets on positive and negative phase blast wave impulses. International Journal of Impact Engineering 2002;27:359-376.

3. Remennikov AM. Evaluation of blast loads on buildings in urban environment. In: The 8th International Conference on Structures Under Shock and Impact. 2004. p. 7382.

4. Smith PD, Whalen GP, Feng LJ, et al. Blast loading on buildings from explosions in City Streets. Proceedings of the Institution of Civil Engineers-Structures \& Buildings 2001;146(1):47-55.

5. U.S. Department of Army Technical Manual (TM5-1300). Design of structures to resist the effects of accidental explosions. Washington, D.C.; 1990.

6. U.S. Department of Army Technical Manual (TM5-855-1). Fundamentals of Protective Design for Conventional Weapons. Washington, D.C.; 1986.

7. Remennikov AM. A Review of methods for predicting bomb blast effects on buildings. Journal of Battlefield Technology 2003;6(3):5-10.

8. Century Dynamics. AUTODYN 2-D \& 3-D User's Manual; 2003.

9. McGlaun JM, Thomson SL, Elrick MG. CTH: A three-dimensional shock wave physics code. International Journal of Impact Engineering 1990;10:351-360.

10. Armstrong BJ, Rickman DD, Baylot JT, et al. Code validation studies for blast in urban terrain. In: Proceedings of 2002 HPC User's Group Conference. 2002.

11. Rose TA. Air3D User's Guide. 7.0: RMCS, Cranfield University, UK; 2003.

12. Fairlie GE, Johnson NF, Moran KC. Validated numerical simulations of blast loads

on structures. In: 16th International Symposium on Military Aspects of Blast and Shock. 2000.

13. Bevins TL, Armstrong BJ, Baylot JT, et al. Multiple building simulations and effect of berms behind blast barrier walls. In: Proceedings of the 2003 HPC User's Group Conference (DoD UGC'03). 2003.

14. Smith PD, Rose TA, Green JA. The effect of arrays of suburban buildings in providing shielding from blast. In: The 11th International Symposium on Interaction of the Effects of Munitions with Structures. 2003.

15. Hyde DW. Conwep - Conventional Weapons Effects: Department of the Army, Waterways Experimental Station, US Army Corps of Engineers, Vicksburg; 1992. 


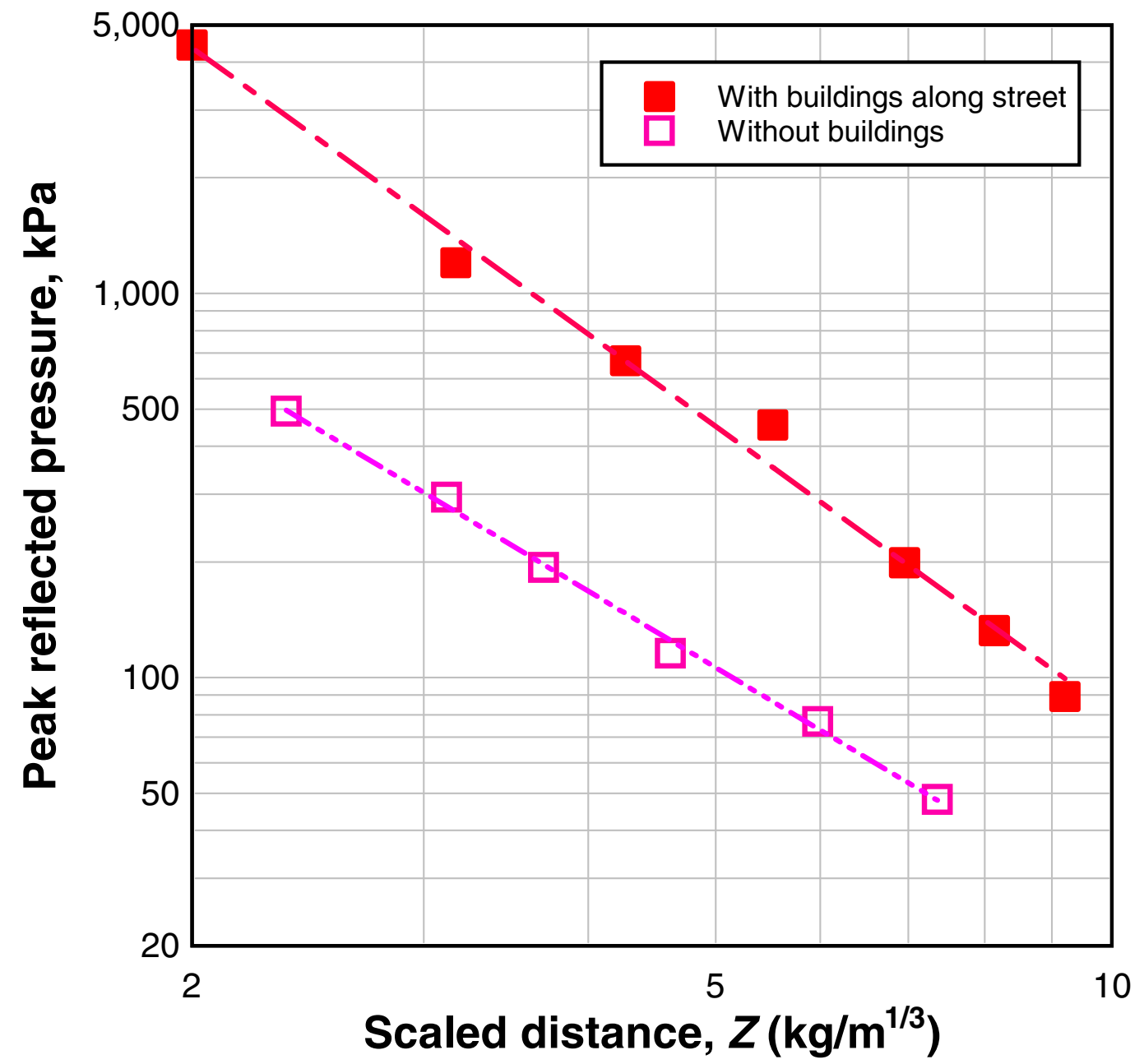

Figure 1. Experimental peak reflected overpressure on target building with and without adjacent buildings (after Smith et al. [4]) 


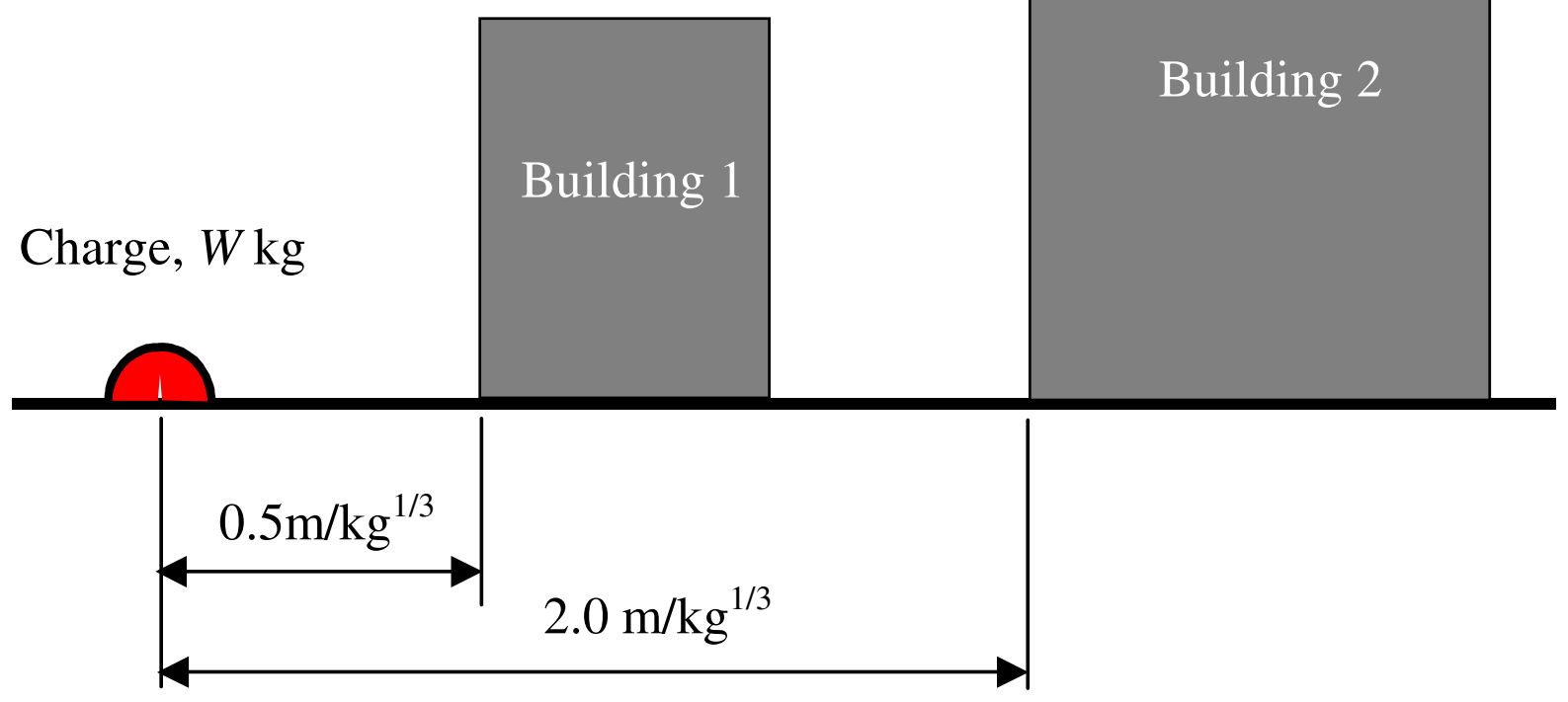

Figure 2. Two-building model showing charge location 

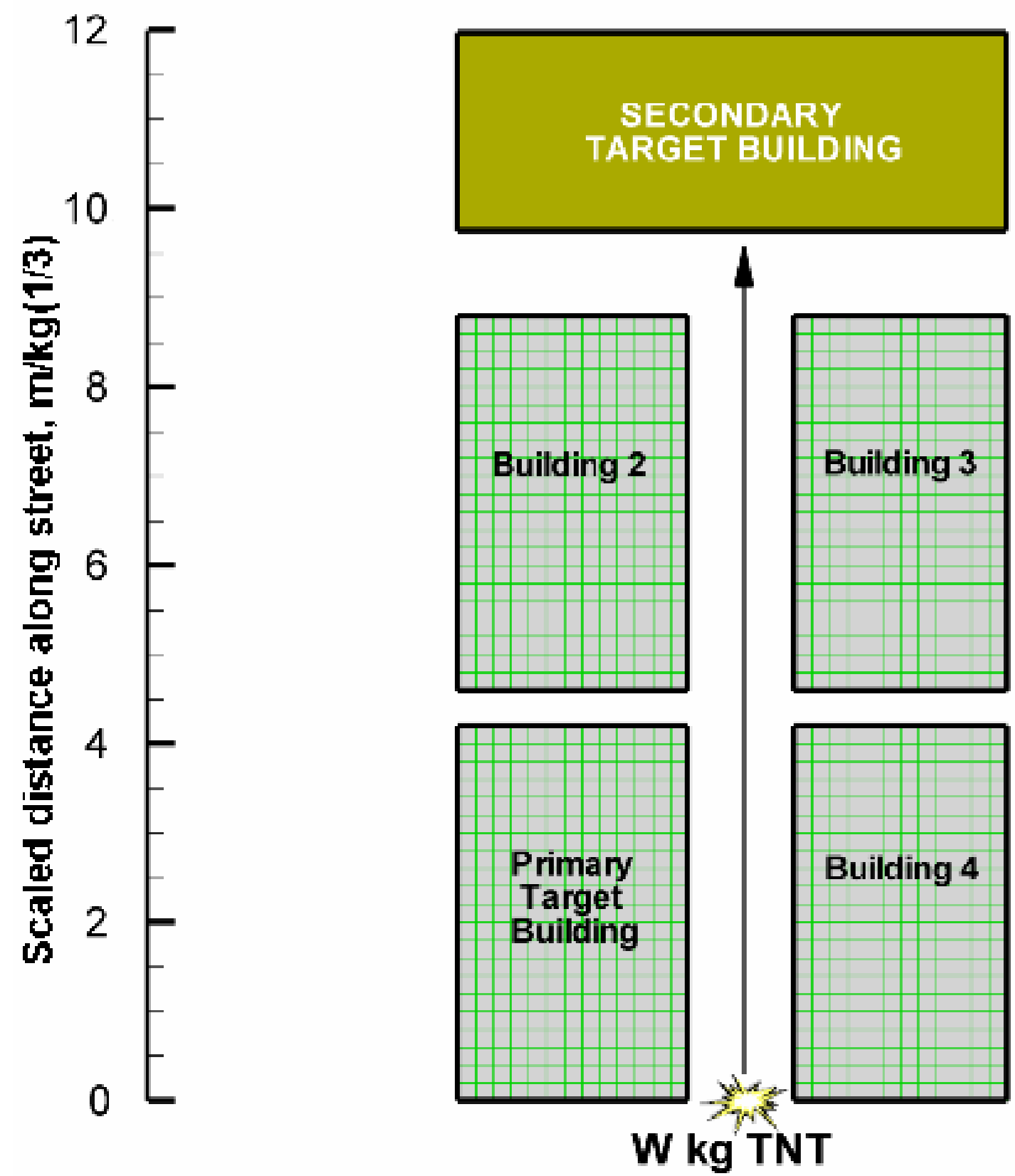

Figure 3. Simulation model for collateral blast effects on a building in city layout 


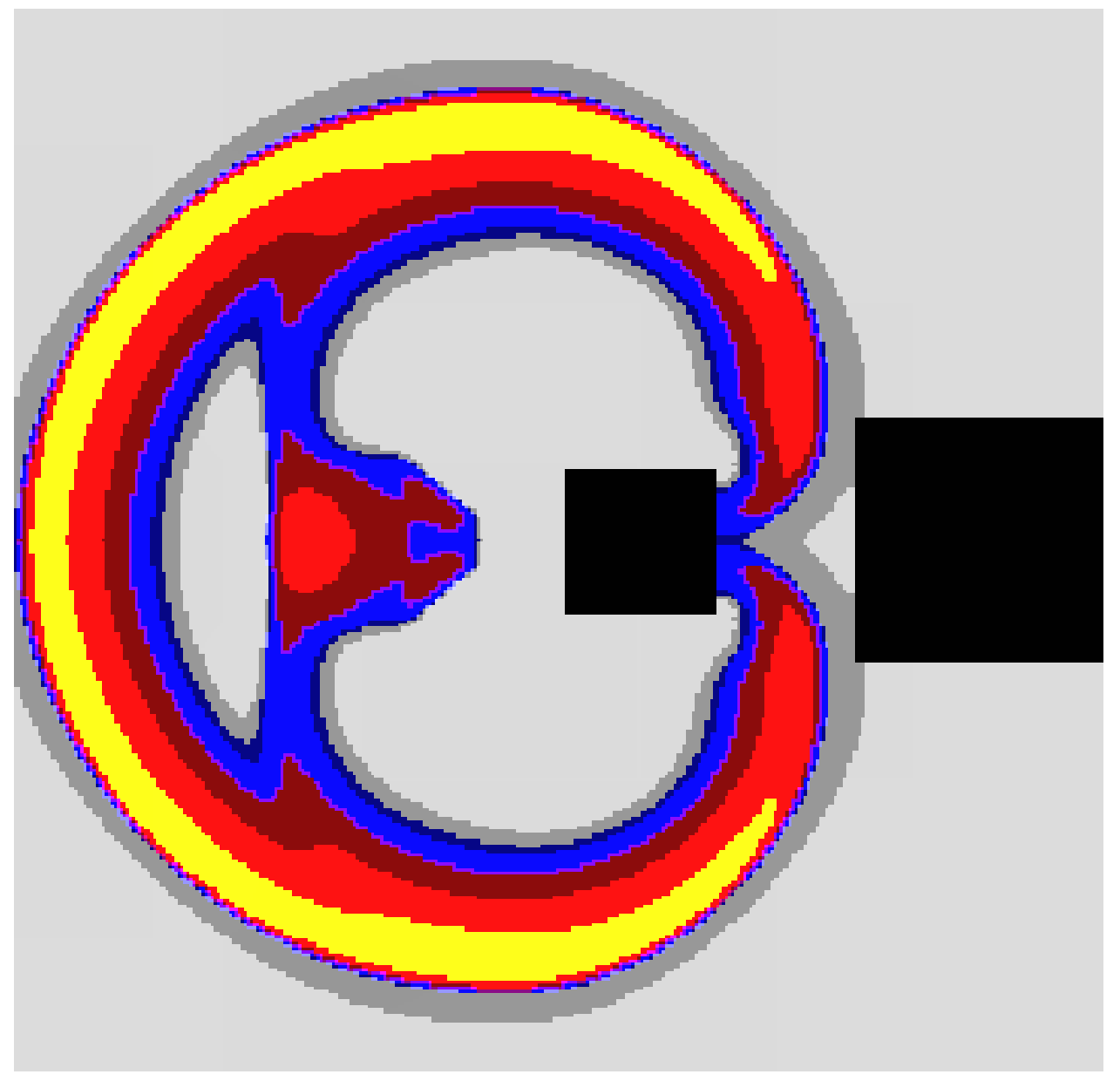

Figure 4. Blast pressure contours after $\mathrm{t}=0.792 \mathrm{msec}$ 


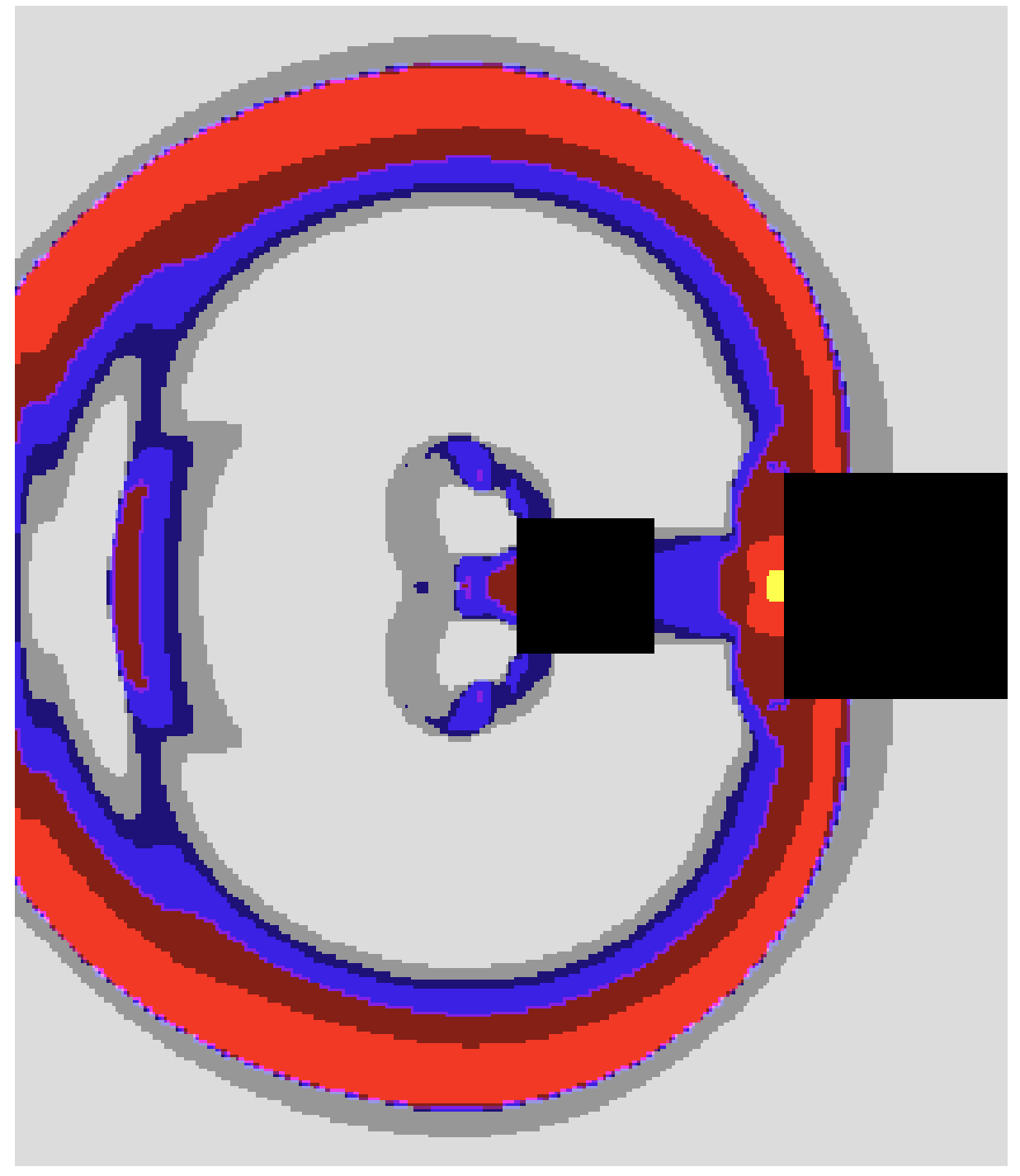

Figure 5. Blast pressure contours after $\mathrm{t}=1.27 \mathrm{msec}$ 


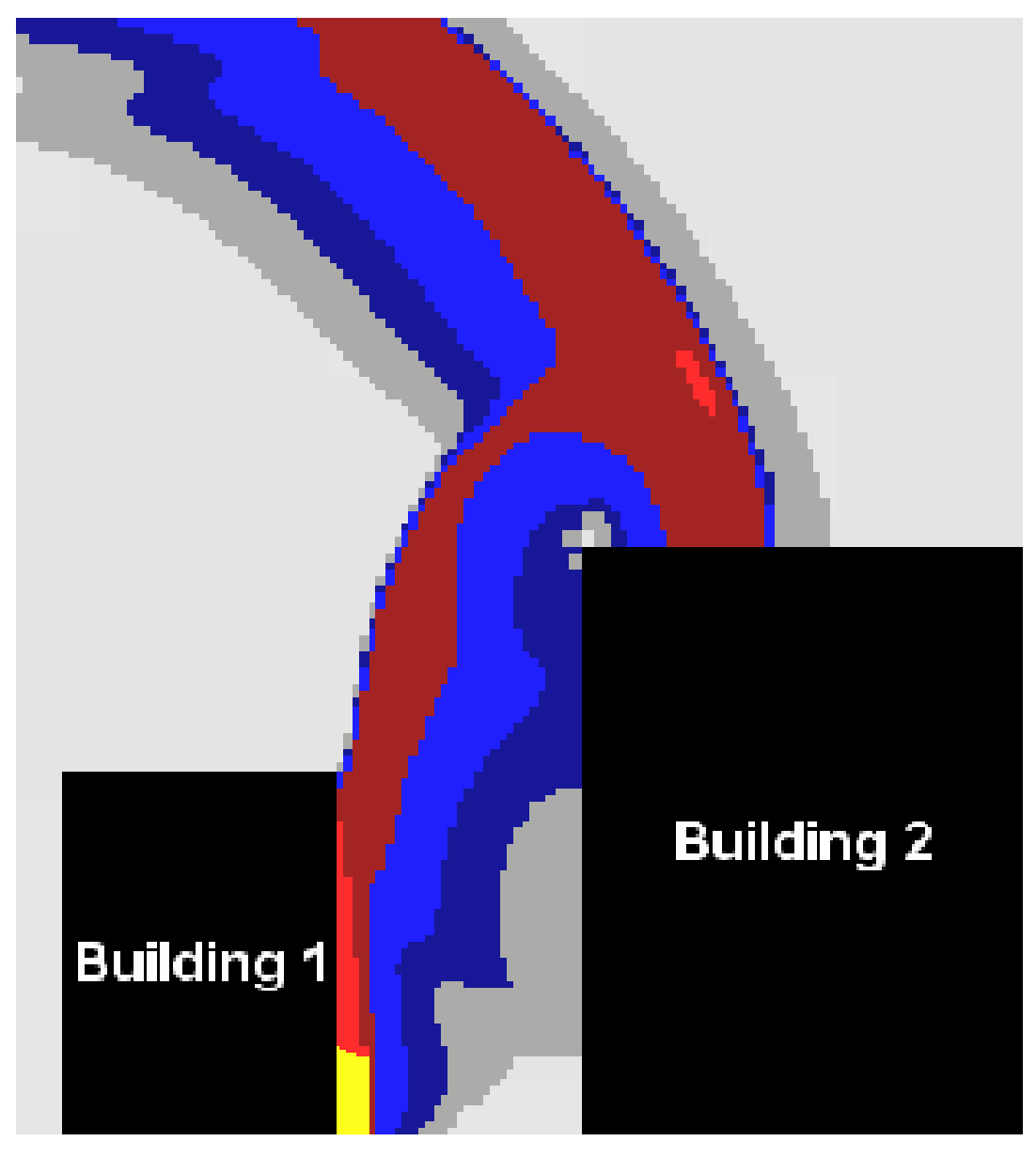

Figure 6. Blast pressure contours after $\mathrm{t}=1.93 \mathrm{msec}$ 


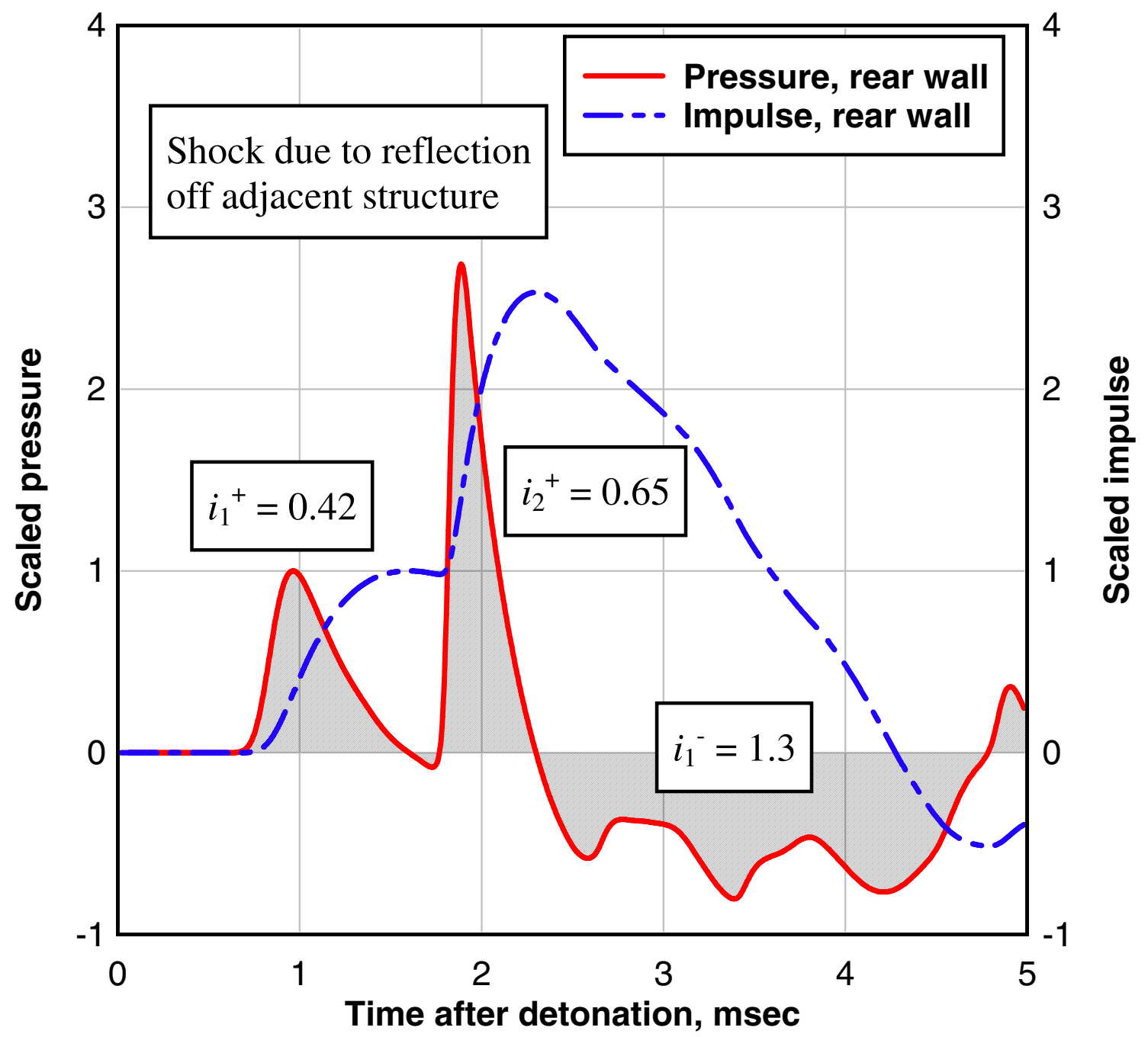

Figure 7. Blast pressure and impulse histories on rear wall of Building 1 


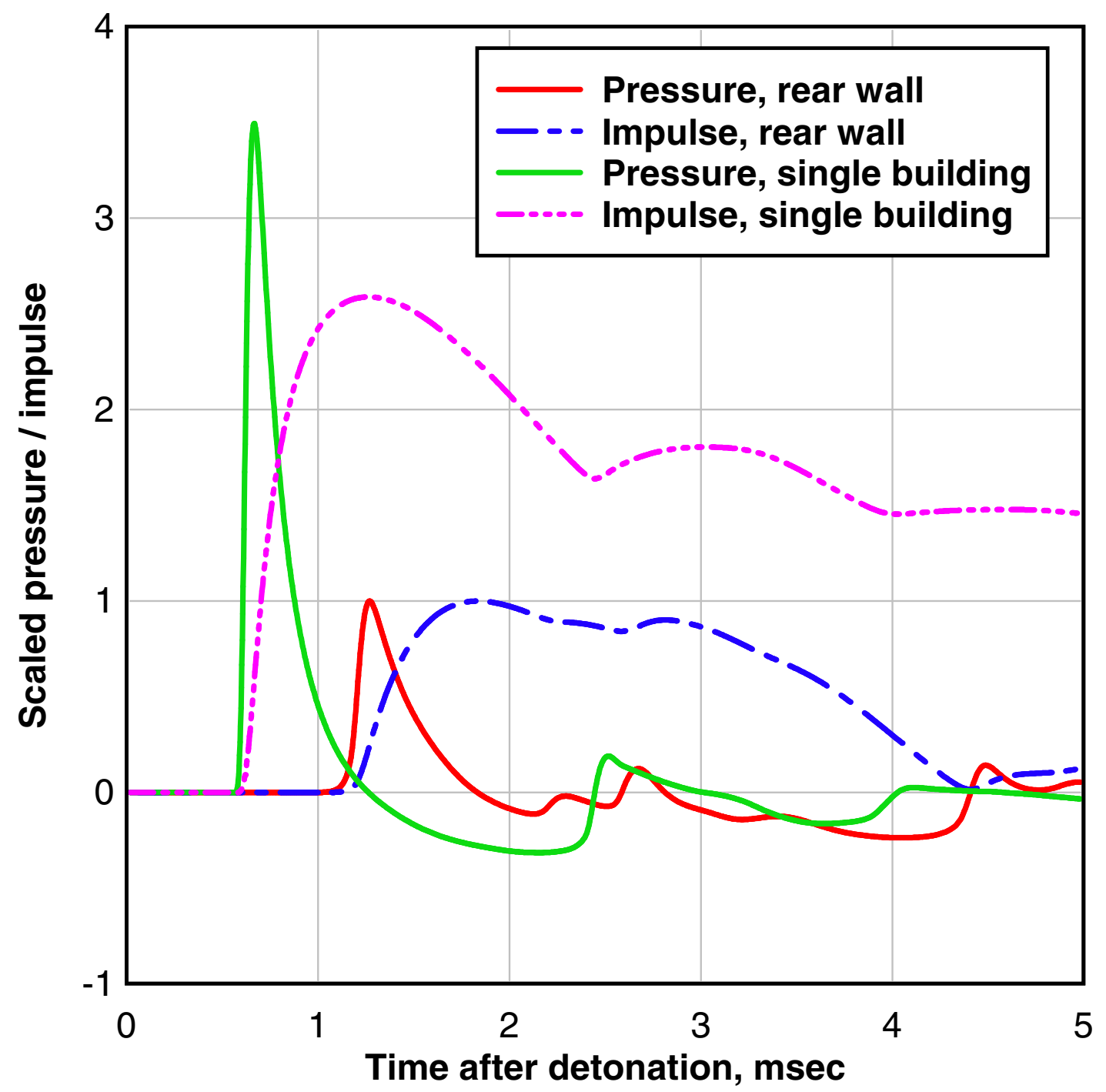

Figure 8. Comparison of pressure/impulse histories on front wall of Building 2 for single- and two-building simulations 

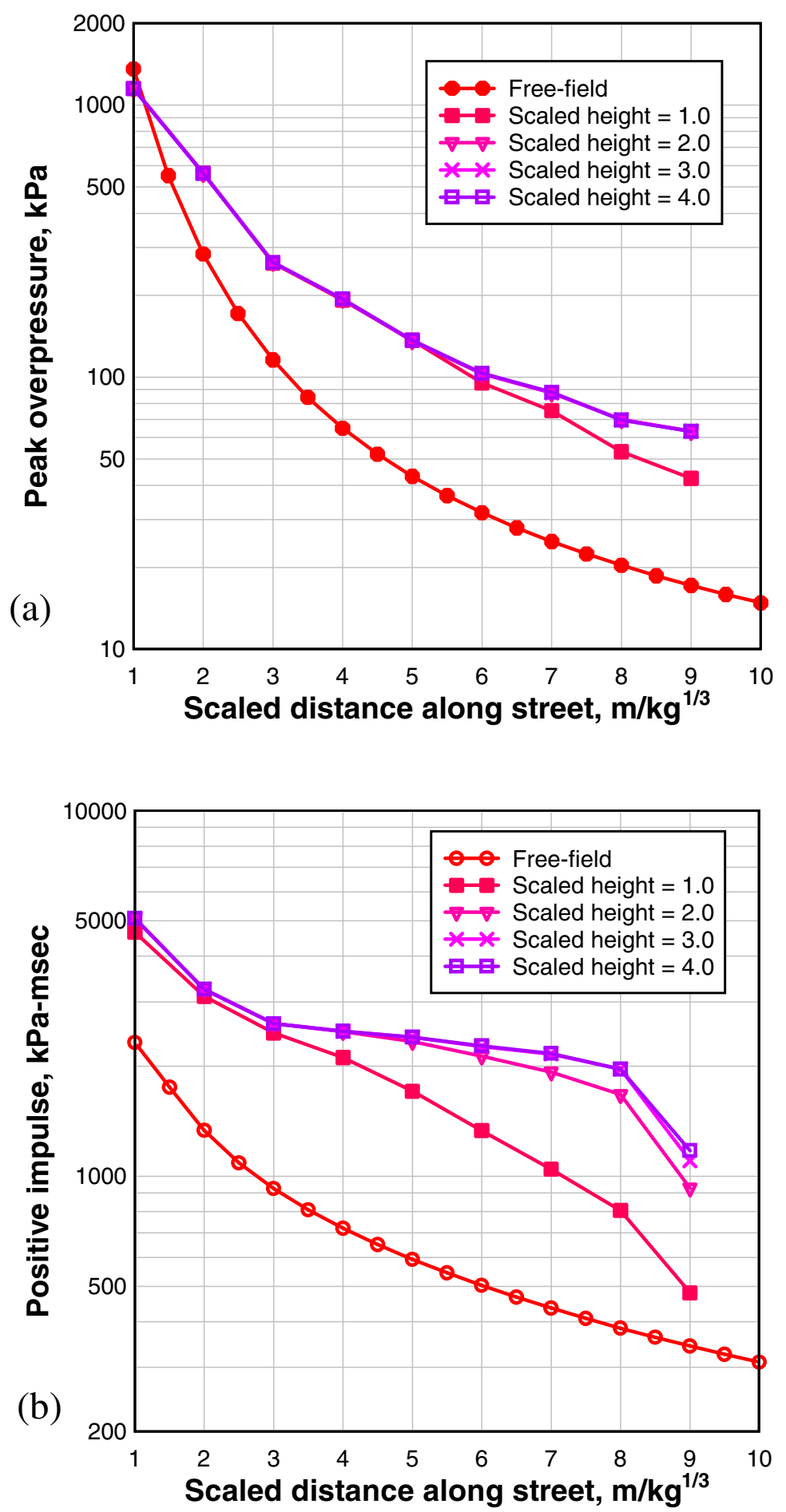

Figure 9. Distribution of the peak overpressures and impulses enhanced by blast focussing along the street 


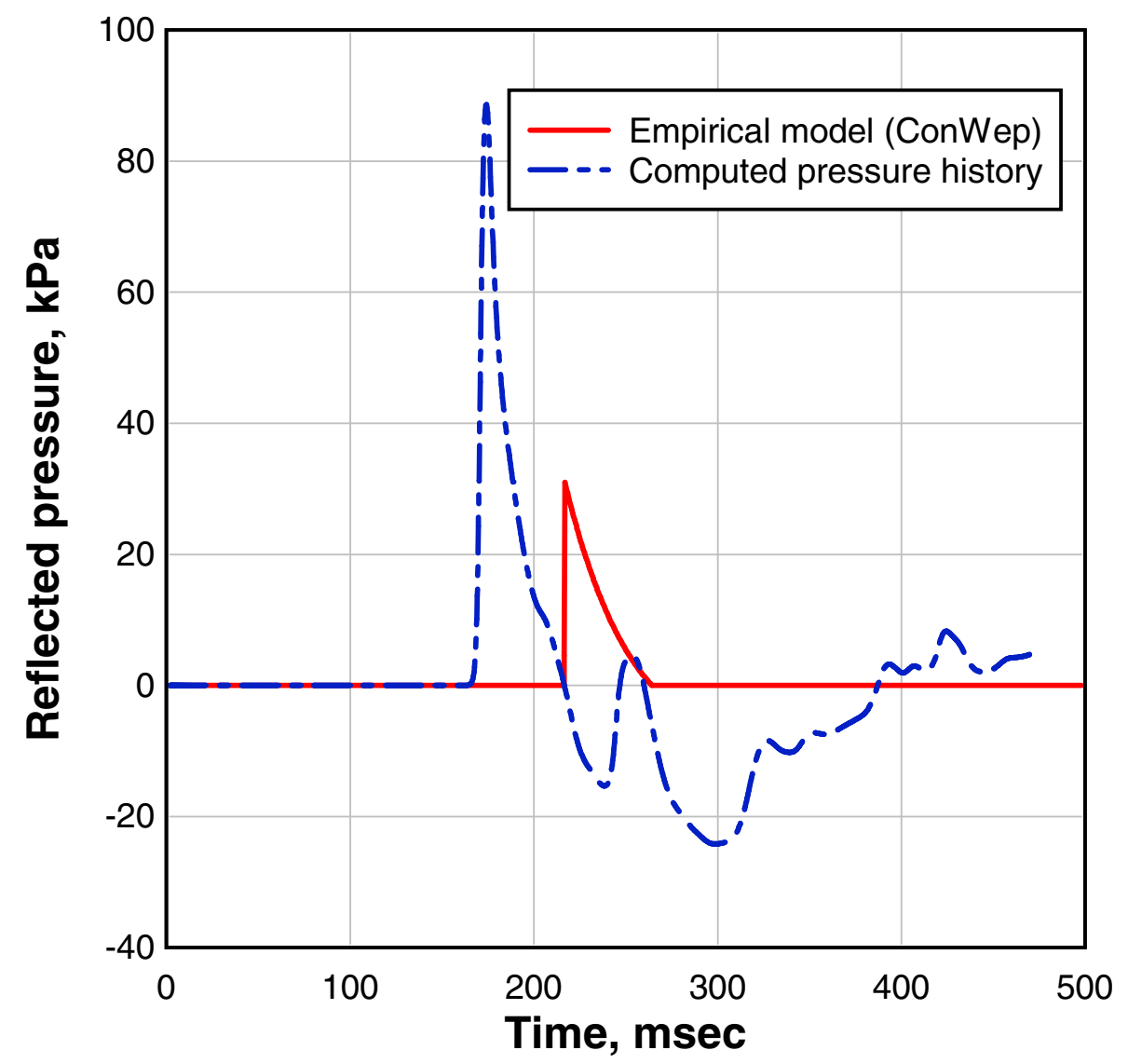

Figure 10. Reflected pressure time history at base of target building. 


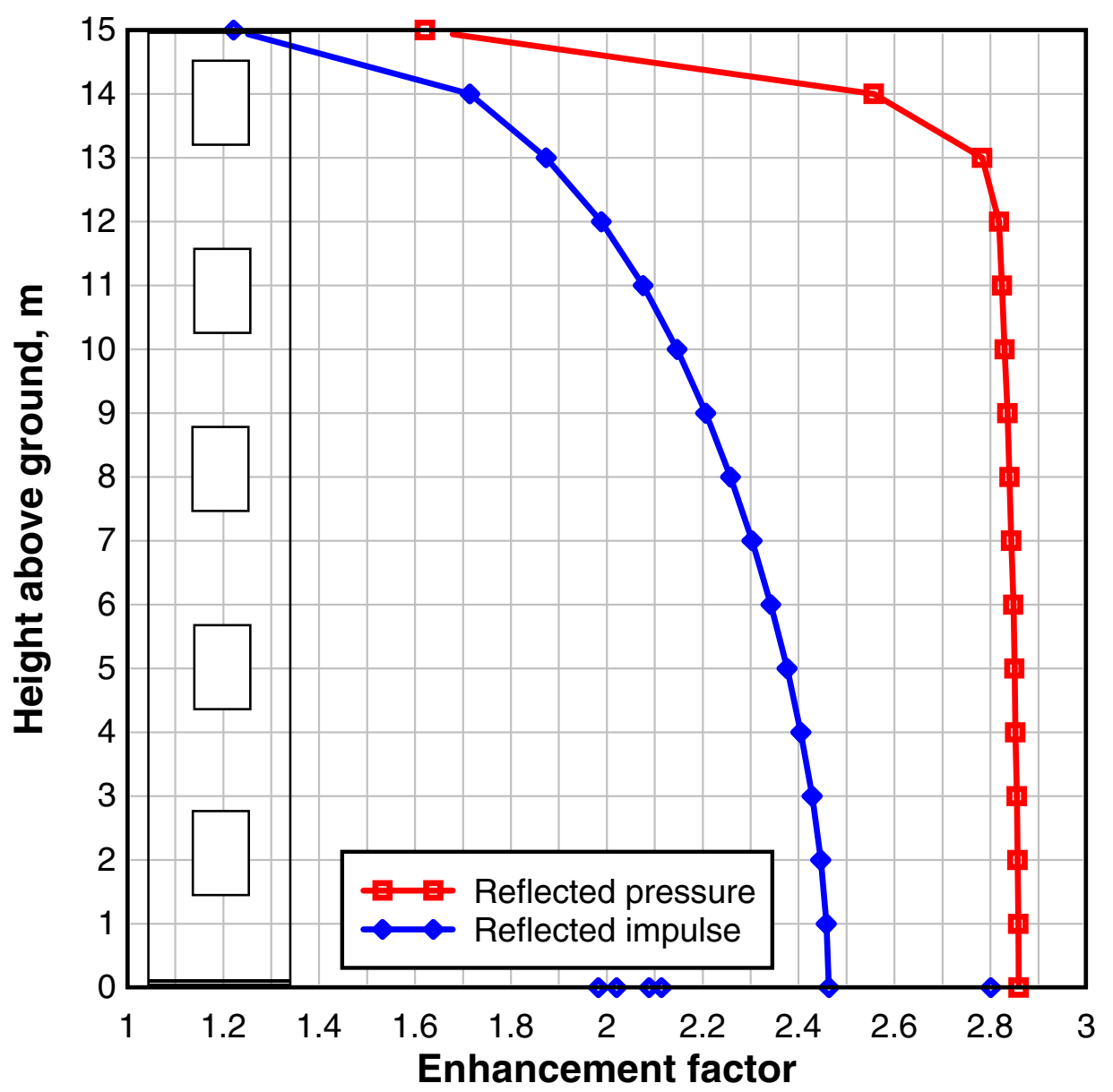

Figure 11. Reflected pressure and impulse enhancement factors along height of front wall of secondary target building. 